\title{
The Application Status Quo of Sports Biomechanics in China's Gymnastics Training
}

\author{
Shuangjun Li, Ailan Dan \\ Department Of Physical Education, Hubei University of Science and Technology, Xianning, HuBei, \\ China \\ 664847109@qq.com
}

Keywords: Application, Sports Biomechanics, Gymnastics, Trainning.

\begin{abstract}
By using the methods of literature and conference discussion, this essay has comprehensive summarized the application status quo of sports biomechanics in China's gymnastics training. The results show that: the application of sports Biomechanics in gymnastics training has been made some achievements, mainly reflected in scientific and technological services of high level sports teams. Based on the characteristics of items, and adopt qualitative and quantitative analysis to constantly pour internal drive for the development of China's gymnastics.
\end{abstract}

\section{Introduction}

Sports Biomechanics is an important branch of sports science, through the objective description, interpretation and evaluation of human movement behavior, to provide a theoretical basis for improving and perfecting the technique, selecting and optimizing the technical program [1]. In this paper, an overview of biomechanics research in gymnastics has been summarized. The purpose is to accurately grasp the developments of sports biomechanics research in this field.

\section{The Application Process of Sports Biomechanics in Gymnastics}

30 years of the 20th century, McCloy showed great enthusiasm in sports Biomechanical research, 20 years after, Wettstone and his graduate students began to study biomechanics on human posture analysis about the general question, "What kind of who has a good gymnastics potential."

60 years of the 20th century, sports science and biomechanics had been established and widely used in gymnastics as a sub-discipline. With the rise of bio-mechanics research in gymnastics, Germany, Japan, the Soviet Union and the United States launched a series of studies, which also contributed to the field of sports biomechanics in competitive research in the extensive application.

20th century 70s, Biomechanics research in gymnastics focused on two areas: kinematic description and kinetic description. Among them, kinematic description mainly used the data analysis of action feature film to analyze technique [2]. Kinetic description mainly used the data of kinetics to design a method for optimizing the technical action.

The beginning of the 20th century 80's, mathematical modeling had been progressive introduced into the research of gymnastics training. The researchers used mathematical models to carry out individual research and targeted individual comparative study. Specifically applied on the modeling analysis of the technique and mechanics features of elite gymnastics, or find the differences between the ideal model and the development models, to help athletes improve and enhance the technique specifications.

In 1980, China established the institute of sports biomechanics. In subsequent decades, most studies focus on biomechanical analysis of technique and has contributed directly to raise the level of competitive sport in China. At present, the sports biomechanics and anatomy, physiology, medicine, rehabilitation, gradually close the combination of learning, the level of research has been greatly improved.

In general, with the development of sports biomechanics and the promotion of science and technology in china, the application of sports biomechanics in sports training and competition is in the way of independence, individualization, specialized technology and digital step by step. At 
present, China has basically formed three Biomechanical analysis system which composed by the kinematics, kinetics and EMG measurement [3].

\section{The overall Idea of Biomechanical Study in China's Gymnastics Training}

Sports training and competition is the "dual core" component of competitive sport. With the development of competitive sports level, scientific training dependence on the basic subject increasingly obvious. Sports biomechanics is the main theoretical basis of scientific and technological research, will long continue to provide scientific and technical services for competitive sports in our country through its right perspective and unique analysis capabilities.

In accordance the dominant factor of competitive ability in item group theory, gymnastics are the item in skills related group, so sports technology is the starting point of item characteristics research. In the technical elements of the movement, body position, movement trajectory, action and rhythm elements can describe the qualitative characteristics of technique; movement time, movement speed, movement rate, movement power can describe the quantitative characteristics of technique.

At present, China's sports biomechanics research concentrate in the comprehensive diagnosis and detection for movement technique [4]. And a perfect research model has been formed. based on the diagnosis of movement technique patterns, we can obtain a large number of data about human action and its associated things, to innovate gymnastics technological and present the formation of scientific evidence.

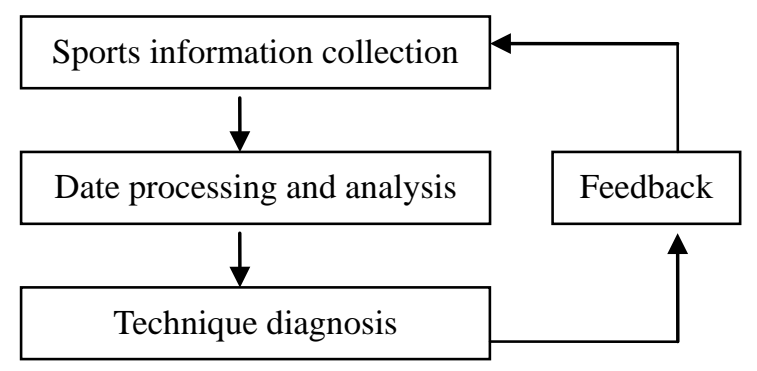

Fig. 1 The basic pattern of diagnosis on Sports Technology

\section{Sports Biomechanics in Research Methods in Sports}

In 2008 Beijing Olympic Games, Chinese gymnastics team made brilliant achiviement, that won 9 gold, 1 silver and 4 bronze. In this process, Sports biomechanics contributed to the scientific and technological support. Here, the main current sports biomechanics research methods to gymnastics show as the following.

Campaign site feedback system. Campaign site feedback system consists of cameras, computers and software elements collection. Kinematics of the main methods of measuring high-speed photography and video. This is a non-contact method of quantitative measurement, without affecting the process of training and competition cases, and by sports technique video camera access to human kinematic parameters [5]. These parameters can be found by analyzing the advantages and disadvantages of movement techniques to explore the principles of sports technology and sports law, provide the basis to enhance athletic performance.

Video processing and rapid feedback. Compare the elite athletes training and competition in China with ones in abroad, then edit the video data and burn CDs, Feedback to the coaches and athletes in order to observe and analyze the problems that them repeatedly found in their own training and competition, timely corrective action in order to promote improvements in technology, on the other hand, analyzes the advantages and disadvantages of foreign athletes Technique, and learn from them.

Technique video image database. We have established the technical action video image databases, which include the the video recording information of international gymnastics competition, such as the Olympic Games, World Championships, World Cup, intercontinental 
events, domestic compitition,as well as training and small test video recording information within the team. We can use these resources to obtain different information about movement technique.

Athletes joint strength test. Muscle mechanics research is basic research, which is the most attractive and most challenging fields in sports biomechanics study. The mechanism of human movement is that bones are the lever, joints are the hub and muscle generates power. The determination of muscle strength index can be used to understand activities ability of athlete and power level, provide a theoretical basis for sports training. The main method is the testing and analysis of athletes joint strength, the content include testing of the hip, knee, shoulder, back and other joint muscle strength in. various flexed, extended speed[6,7].

Sports biomechanics research of new and difficult technology. This method include two-dimensional and three-dimensional kinematic analysis. The features of two-dimensional kinematic analysis are fast, intuitive, information is less and easy to understand, more suitable for coaches and athletes. It is chiefly used in Comparing research of different techniques, comparative analysis of the key kinematic index of movement technology, such as key instantaneous displacement, angle, height, speed, etc. (Table 1).

Table 1 vault action process, changes in mechanical parameters

\begin{tabular}{|c|c|c|}
\hline Index & $\begin{array}{l}\text { backflip } 540^{\circ} \\
\text { swivel }\end{array}$ & $\begin{array}{l}\text { backflip } 720^{\circ} \\
\text { straight }\end{array}$ \\
\hline The level speed before the pedal & $4.9 \mathrm{~m} / \mathrm{s}$ & $5.3 \mathrm{~m} / \mathrm{s}$ \\
\hline $\begin{array}{l}\text { The hip away from the plate - the angle } \\
\text { between the horizontal angle of tip connection }\end{array}$ & $91.9^{\circ}$ & $86.2^{\circ}$ \\
\hline $\begin{array}{l}\text { Hand tip - toe angle and horizontal } \\
\text { connections }\end{array}$ & $111.7^{\circ}$ & $110.5^{\circ}$ \\
\hline $\begin{array}{l}\text { Shoulder - hand angle of connection with the } \\
\text { level of }\end{array}$ & $51.6^{\circ}$ & $56.7^{\circ}$ \\
\hline $\begin{array}{l}\text { Real Hip - hand angle of connection with the } \\
\text { level of }\end{array}$ & $31.3^{\circ}$ & $39.5^{\circ}$ \\
\hline $\begin{array}{l}\text { Instantaneous shoulder - hand connection and } \\
\text { the horizontal angle }\end{array}$ & $66.1^{\circ}$ & $73.3^{\circ}$ \\
\hline Vacated the highest point of the course focus & $1.31 \mathrm{~m}$ & $1.28 \mathrm{~m}$ \\
\hline
\end{tabular}

The Data is adapted from the course of first key Laboratory in 2010. The characteristics of three-dimensional kinematic analysis are cycle length, flexible, comprehensive information, a heavy workload. For example, the kinematic analysis of "Chen Fei jump", we used two high-speed video camera which are on the one side of runway, shooting frequency was 125 frames/sec. Two shooting both were calibrated by three-dimensional framework of PEAK, using external synchronization deal with the technique. The data that got from SIMIMOTIION software analysis, were smoothed by the low-pass filter and the cutting off frequency was 8HZ.

According to multi-body system dynamics, using of simulation technology and MSC.ADAMS / LIFEMOD software, set up a model that similar to the human body of 19 links, 52 degrees of freedom, create a model of the link. Then, The three-dimensional coordinates of body joints were obtained from kinematics analysis, combined with three-dimensional human body model to reconstruct the human body posture, three-dimensional model through the reverse dynamic and forward dynamics simulation analysis, can generate human animation and for a variety analysis of human movement.

\section{Summary}

The application of sport biomechanics in gymnastics has been made certain achievements, mainly reflected in scientific and technological service of high level sports teams. The chief methods are campaign site feedback system, video processing and rapid feedback, technique video 
image database, athlete's joint strength test, sports biomechanics research of new and difficult technology.

Despite the current achievements deserve recognition, but not difficult to find that a lot of advanced equipment and human resources of sports biomechanics are mainly concentrated in high-level teams. Biomechanics support for basic training is relatively weak. Most coaches and athletes feel difficult on the understanding and application of relevant information.

The approach that in order to promote the comprehensive development of sports biomechanics as follows:increasing of advanced measuring equipment and test tools, breakthrough of start modeling and simulation for difficult and new technique, focus on training of sports biomechanics and sports training complex Talent, positive launch basis applied research of sports biomechanics.

\section{Acknowledgements}

The study was sponsored by XNSK-Y1433 Fund.

\section{References}

[1] H.H. Feng, H.B. Zhao, J. Ye and Y.Q. Li. Chinese sports biomechanics research and development status and development trend. China Sports Science, 2009,45 (3).

[2] H.J. Lu, Feathers. Biomechanics in China nearly a decade of research and development trend 2000 to 2009, nearly a decade the core journals published in Sports Biomechanics paper to study. Science and Technology Innovation Review, 2010, Phase II, 1-2.

[3] W.Y. Hao, Pang Le. a retiring welcome. Chinese Gymnastics Team for the Beijing Olympic Games Integrated Services Biomechanics in research. The 29th Olympic Games (2008, Beijing) results of scientific research and technology service set, 2009.

[4] State Key Laboratory of State Key Laboratory of General Administration of sports training class material assembly.2010.

[5] Ellen kreighbaum. Biomechanics research in gymnastics: past, present and future.2008

[6] W.X. Peng, L.H. Wang, Z. Lin, M.L. and M.L. Zhang. Identification and Chemical Bond Characterization of Wood Extractives in Three Species of Eucalyptus Biomass. Journal of Pure and Applied Microbiology, 2013, 7 (SI), 67-73.

[7] W.X. Peng, Z. Lin, J.B. Chang, F.L. Gu, X.W. Zhu and Z.F Zhang. Immunology Molecular Characteristics of JYBS Extractives from Illicium verum Biomass. Journal of Pure and Applied Microbiology, 2013, 7 (2), 1237-1243. 